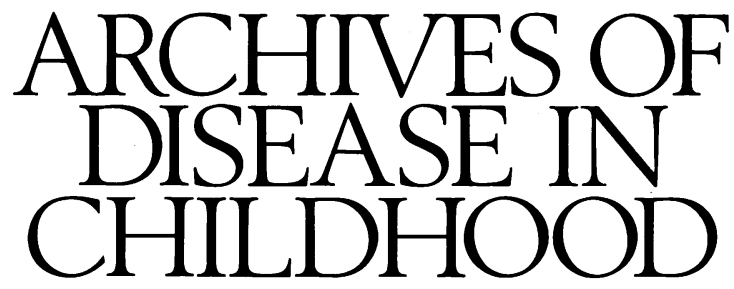

The Fournal of the British Paediatric Association

\title{
Annotations
}

\section{Cleft lip_-is there light at the end of the tunnel?}

Cleft lip, with or without cleft palate $(\mathrm{CL} / \mathrm{P})$, is one of the commonest serious craniofacial malformations with an incidence of between one in 700 and one in 1000 live births. There can be little doubt about the impact the birth of an affected child has on a family. Problems with bonding and feeding are usually overcome with appropriate support and advice. Several operations may be needed throughout the growing years, as well as long term follow up by a team of specialists: plastic surgeons, orthodontists, ear, nose, and throat surgeons, speech therapists, dentists, and others. Despite advances in surgical and psychological management, there remains considerable confusion about the genetic implications of cleft lip. Is it a 'genetic' condition? Can parents be given an accurate risk of recurrence of this malformation? Current research looks set to answer, at least in part, some of these questions.

Family studies have shown that, after the birth of a child with isolated $\mathrm{CL} / \mathrm{P}$, the average recurrence risk for a couple with no family history of clefting is in the region of one in $25,{ }^{1}$ the figure varying with the severity of the cleft. The same figure applies for the child of a couple where one partner has $\mathrm{CL} / \mathrm{P}$. This 40 -fold increase in risk over the general population suggests that some inherited element is important in the production of a cleft lip.

The presence of a family history of CL/P significantly increases the risk of recurrence. In this situation it is obviously essential first to differentiate between isolated $\mathrm{CL} / \mathrm{P}$ and $\mathrm{CL} / \mathrm{P}$ occurring as part of one of the many mendelian disorders with this as a feature. These include, for example, the Van der Woude's syndrome $(\mathrm{CL} / \mathrm{P}$ with lip pits) and EEC syndrome (ectrodactyly-ectodermal dysplasia-clefting), both autosomal dominant conditions.

Many chromosomal aneuploidies (for example, trisomy 13 and trisomy 18) and a large number of other chromosomal rearrangements are also associated with $\mathrm{CL} / \mathrm{P} .^{2}$ About $10 \%$ of cases of $\mathrm{CL} / \mathrm{P}$ are associated with cther malformations. ${ }^{3}$ Children with the rarer types of cleft, such as oblique facial clefts, tranverse facial clefts, clefts of the lower lip, and median clefts of the upper lip, frequently have other problems-the latter particularly being associated with midline abnormalities of the brain such as agenesis of the corpus callosum and holoprosencephaly.

In the past almost every possible mode of inheritance has been postulated for $\mathrm{CL} / \mathrm{P} .{ }^{+}$Generally, the most widely accepted model is that of multifactorial inheritance, whereby the trait is determined by a number of genes at different loci interacting with various, largely unknown, environmental factors. However, some families exist where $\mathrm{CL} / \mathrm{P}$ appears to be inherited as an autosomal dominant trait, albeit with incomplete penetrance and variable expression. It would seem that, in such families, a major gene is being passed from parent to child causing cleft lip. As it stands at present genetic counselling for $\mathrm{CL} / \mathrm{P}$ is less than satisfactory, with couples being given an empirical recurrence risk after the birth of an affected child. If they then go on to have another affected child their risk increases further still as they have shown themselves to have a significant genetic predisposition. Identification of genetic loci that predispose to $\mathrm{CL} / \mathrm{P}$ will help to distinguish these high risk from the low risk couples before an affected child is born.

A major tool of molecular genetics is linkage analysis, whereby potential candidate genes or genetic markers are studied in suitable pedigrees to see if they segregate with the condition more often than can be accounted for by chance. A number of studies of this type have already been completed and several markers have been excluded or shown to demonstrate weak linkage as a result. ${ }^{56}$ Van der Woude's syndrome has been mapped to the long arm of chromosome $1,{ }^{7}$ and it would obviously be worth checking whether or not this marker shows linkage in other dominant CL/P families without lip pits.

Using genes which are likely, by their known function in either humans or animals, to play some part in lip and palate formation, increases the chance of success in linkage studies. The list of such 'candidate genes' for CL/P is extensive. It includes a number of growth factors such as transforming growth factors $\alpha$ and $\beta$ (TGF $\alpha$ and TGF $\beta$ ). ${ }^{89}$ These are a highly conserved group of polypeptides that have a central role in many embryological processes.

Faced with a large number of potential candidate genes an alternative approach to linkage analysis is an association study. This approach compares genetic variation at a number of gene loci in a large group of unrelated individuals with $\mathrm{CL} / \mathrm{P}$ with that of a group of matched controls. The hypothesis is that one specific mutational event in a candidate gene might underlie a substantial proportion of clefting in the white population. Such a study has recently demonstrated a significant association between $\mathrm{TGF}\left(\ell\right.$ and $\mathrm{CL} / \mathrm{P}{ }^{8}$

Another approach is to use gene probes from chromosomal regions which have been shown to be associated with $\mathrm{CL} / \mathrm{P}$ when disrupted. The problem with this approach is that $\mathrm{CL} / \mathrm{P}$ appears to be a relatively non-specific response to chromosome imbalance. Certain patterns are emerging, and the short arm of chromosome 6 would seem to be of particular interest as it has been implicated in linkage studies, ${ }^{6}$ and in chromosomal deletions resulting in $\mathrm{CL} / \mathrm{P}$ as part of the clinical phenotype. ${ }^{10}$ It is also the localisation of the human 
homologue of a gene known to cause a cleft like abnormality in the mouse. ${ }^{11}$ Similarly, two unrelated cases of CL/P with translocation breakpoints at $10 \mathrm{p} 13$ have now been described, making this another area of potential study. ${ }^{12}$

The identification of a major locus is unlikely to be the end of the story. CL/P is almost certainly heterogeneous with other modifying genes playing some part in the development of a cleft. Also environmental factors, such as maternal phenytoin ingestion, are known to predispose to facial clefting, and it is possible that some continuous traits, such as face width, play a part.

The practical implication of the present research is the identification of individuals with a genetic predisposition to facial clefts. Prenatal diagnosis, with a view to termination of an affected fetus, tends not to be an issue in this condition, which is essentially amenable to surgical repair. Many couples do currently take up the option of a detailed ultrasound scan at about 18 weeks of pregnancy, as a noninvasive means of detecting the anomaly during pregnancy, and this allows them to prepare for the birth of an affected child.

Kennedy-Galton Centre,

Northwick Park Hospital,

Watford Road,

Harrow,

Middlesex HAI $3 U \mathcal{F}$
Dr Sue Holder is supported by the Medical Research Council. Thanks go to Dr RM Winter for his help with the preparation of the manuşcript.

1 Harper PS. Practical genetic counselling. London: Wright, 1988:188-9.

2 Schinzel A. Catalogue of unbalanced chromosome aberrations in man. Berlin New York: de Gruyter, 1983:850-1.

3 Gorlin RJ, Cohen MM Jr, Levin LS. Syndromes of the head and neck. New York/Oxford: Oxford University Press, 1990:698.

4 Fraser FC. Mapping the cleft-lip genes: the first fix? [Editorial.] Am f Hum Genet 1989;45:345-7.

5 Spence MA, Glass L, Crandall BF, et al. Genetic linkage studies with cleft lip and palate: report of two family studies. $\mathcal{F}$ Craniofac Genet Dev Biol 1983;3: and palate:

6 Eiberg H, Bixler D, Nielsen LS, Conneally PM, Mohr J. Suggestion of linkage of a major locus for nonsyndromic orofacial cleft with F13A and linkage of a major locus for nonsyndromic orofacial cleft with F13A
tentative assignment to chromosome 6. Clin Genet 1987;32:129-32.

7 Murray JC, Nishimura DY, Buetow $\mathrm{KH}$, et al. Linkage of an autosomal dominant clefting syndrome (Van der Woude) to loci on chromosome lq. dominant clefting syndrome (Van de
Am $\mathcal{F}$ Hum Genet 1990;46:486-91.

8 Ardinger HH, Buetow KH, Bell GI, Bardach J, VanDemark DR, Murray JC. Association of genetic variation of the transforming growth factor-alpha gene with cleft lip and palate. Am $\mathcal{F}$ Hum Genet 1989;45:348-53.

9 Fitzpatrick DR, Denhez F, Kondaiah P, Akhurst RJ. Differential expression of TGF beta isoforms in murine palatogenesis. Development 1990;109: 585-95.

10 Kormann-Bortolotto MH, Farah LMS, Soares D, Corbani M, Muller R, Adell ACA. Terminal deletion 6p23: a case report. Am $\mathcal{F}$ Med Genet 1990; 37:475-7.

11 Wakasugi $S$, Iwanaga $T$, Inomoto $T$, et al. An autosomal dominant mutation of facial development in a transgenic mouse. Developmental Genetics 1988;9:

12 Human Gene Mapping 10·5. Cytogenet Cell Genet 1990;55:335.

\section{Adrenoleucodystrophy}

There are few diseases more tragic than adrenoleucodystrophy (ALD). In a typical case a boy of between 5 and 9 years of age starts to have behavioural problems, difficulty with school work, becomes forgetful, and has problems finding his way about. He often appears to have difficulty in seeing, but is not obviously blind. He then starts to have further problems with memory and language. Within weeks or months the situation progresses so that he has some degree of unsteadiness, becomes incoordinated, and starts to fall. Still later on in the course of the disease his vision obviously becomes worse, and optic atrophy may be noted. He may become ataxic, dysarthric, and hemiparetic, and he starts to dement clearly. Seizures, often focal, are a late feature of the condition, but often within a year tragically the boy becomes bedridden and death usually ensues from intercurrent infections or complications of seizures within two to three years.

Although a number of early cases described as Schilder's disease $^{1}$ (encephalitis periaxalis diffusa) may have been cases of ALD, the first clear description of what we now know to be ALD was by Siemerling and Creutzfeldt. ${ }^{2}$ Sometimes the name Addison-Schilder's disease has been applied in the past. Addison's name was added because occasionally these boys may develop dark skin pigmentation (melanoderma) associated with adrenal hypofunction and occasionally go into adrenal crisis. They may present with Addison's disease and then develop the ALD picture later on or vice versa. Over the past 10 years we have begun to understand much more about the nature of the disease, its pathology, and underlying metabolic and molecular abnormalities. As yet there is no effective treatment, although some dietary trials are in progress. ${ }^{3}$

From a clinical point of view there are a number of variants. The most common variant is the childhood form described above. The condition may present in a similar form in adolescence and progresses in much the same way, although the whole process is slower. The condition may also present as a slowly progressive spastic paraparesis which is associated with adrenal dysfunction, so called adrenomyeloneuropathy, ${ }^{4}$ here too the paraparesis may precede the Addison's disease. Occasionally an adult may present with a dementia. Although the disease is usually progressive, some patients have phases when the illness plateaus. Moser and Moser have given a very complete description of clinical variants. ${ }^{5}$

The full blown disease appears to be confined to males. There is often a family history of affected boys to suggest an $\mathrm{X}$ linked pattern of inheritance. Although female carriers are usually asymptomatic, some have clinical symptoms. ${ }^{6}$ What is typical of ALD is that there can be a great deal of variation of clinical severity, not only between families but within one family. One member of an extended family could have adrenomyeloneuropathy, another Addison's disease, and a third classical ALD.

Recently the underlying defect has been shown to be a disorder of peroxisomal metabolism. ${ }^{7}$ Peroxisomes are subcellular organelles performing a variety of functions including peroxidation (whence the name derives), the synthesis of plasmalogens which involves acyl CoA:dihydroxyacetone phosphate acyltransferase (DHAPAT), degradation of bile acids and the break down by beta oxidation of very long chain fatty acids. ${ }^{8}$ Peroxisomal disorders have come into prominence recently as the main cause of the Zellweger's group of diseases in some forms of which peroxisomes are absent. ${ }^{910}$ In ALD peroxisomes are present but there is a single peroxisomal enzyme defect now thought to be lignoceryl CoA synthetase. ${ }^{11}$ The biochemical findings in ALD have now been well worked out and include a rise of very long chain fatty acids, particularly $\mathrm{C} 26: \mathrm{O}, \mathrm{C} 24: \mathrm{O}$, but no rise of bile acid intermediates, nor a deficiency of DHAPAT. ${ }^{12}$ What is even more unusual than the variation within a family is that asymptomatic siblings of a propositus 